\title{
DESENCOBRIR O SUL, DESFETICHIZAR O PENSAMENTO
}

\section{UNCOVERING THE THEORETICAL SOUTH, TO DEFETISHIZE THINKING}

\section{Dernival Venâncio Ramos Júnior¹}

...la otra cara, la cara explotada, dominada, encobierta.

Dussel, Enrique. 1492. El encubriento del outro.

Resumo: Neste texto, para situar o que chamo de desencobrir o Sul teórico, relato experiências depelas quais passei no processo educacional. Tomo-as como ponto de partida para a discussão sobre o deslocamento das biogeografias da razão e, proponho, para isso, que ao ler as teorias pós e descoloniais tenhamos em conta o trabalho social necessário à sua construção realizado por autores, movimentos sociais e políticos do Sul. Do mesmo modo, a partir desse reconhecimento, enraizarmos as universidades nas lutas das comunidades de vida, existência e r'existência.

Palavras-chave: desencobrir o Sul; descolonial; desfetichizar o pensamento.

\begin{abstract}
In this text, in order to explain what I called uncovering the theoretical South, I tell you some experiences that I lived in my educational process. It's from them that I discuss the displacement of the biogeographies of reason, and for that, I propose that reading pos and decolonial theories we have in mind that the required social work allows some authors, social movements and politicians from South construct their thoughts. In the same way, after this comprehension, we should connect the universities with the struggles of communities of life, resistance and r'existence.
\end{abstract}

Keywords: uncovering the theoretical South; descolonial; defetishize thinking.

\section{Desencobrir o Sul teórico}

Nos textos teóricos, a vida não é objeto de "contação". É assim, pois, em franca oposição, que escrevo este ensaio.

Quando eu tinha 06 anos, fui levado para a cidade. O objetivo era que eu acessasse o saber escolar, valorizado pelos membros mais velhos da família. Meu pai, um camponês com breves passagens pela vida urbana, tomou conselho com o meu avô e, em comum acordo com

\footnotetext{
${ }^{1}$ Doutor em História pela Universidade de Brasília e professor da graduação em História, do Programa de Pósgraduação em Ensino de História e do Programa de Pós-graduação em Estudos de Cultura e Território do Campus de Araguaína da Universidade Federal do Tocantins. E-mail dernivaljunior@ gmail.com
} 
a minha mãe, desvencilharam-se da Terra² ${ }^{2}$ Eles haviam migrado de Goiás para o Pará em busca de vida melhor e, para minha mãe ao menos, a decisão de vender a posse teve o peso de um sacrifício.

Mais tarde, o ímpeto que orientara meus pais havia se tornado algo meu. Com 15 anos, descobri que, se quisesse continuar a estudar, precisava morar em uma capital. Mudei-me para Goiânia aos 17. Depois de concluir a graduação e o mestrado em História, precisei ir a outra cidade, Brasília - um centro "mais central" -, para fazer doutorado. Por essa lógica, ainda durante o doutorado, estive um ano em Madri, "mais cêntrica ainda".

30 anos depois de sair da roça ${ }^{3}$, a busca continuou nos Estados Unidos e, de novo, na Espanha. Desta trajetória, gostaria de destacar, antes que ela seja glamourizada por alguém, a sua dupla face: alienação e liberdade. À medida que me envolvia com a episteme norteatlântica, alienava-me, em níveis como o político, o epistêmico e o afetivo, do lugar, o Sul do Pará, e da comunidade de vida, existência e saber dentro da qual nascera. Tampava meus olhos por "dentro" 4 .

Mas em novembro de 2014, de novo, pisei o chão. A partir do contato com os movimentos sociais e comunidades, fui percebendo que os autores, as autoras, os sistemas de saber dos sujeitos do Sul foram sendo, ao longo do meu processo de formação acadêmica, encobertos. Abriam-me um mundo e, sorrateiramente, bloquearam em mim a possibilidade de ver a minha realidade como parte dele. A isso eu chamo de norteação.

Não quero dizer que os autores e autorias do Sul não estivessem presentes na formação universitária. Quando apareciam - o que era raro -, eram classificadas como história das ideias latino-americanas ${ }^{5}$. As autorias orais entravam no registro de saberes culturais que "representavam" a realidade (RAMOS, 2019). Seja história das ideias ou como saberes locais (GEERTZ, 1977), o fato é que eram classificados por um “olhar exterior”, antropológico, e percebidos não sem espanto, a partir da retórica, ainda hoje comum, da “descoberta”.

\footnotetext{
2 Terra, na região em que nasci, é o substantivo para nomear a propriedade da família. Mas é percebida também como um nome para o sistema ontoepistêmico camponês do Brasil Central.

3 Roça é uma categoria sociológica de Alfredo Wagner Berno de Almeida (2006).

4 Essa metáfora refere-se ao fato de que a educação escolar, sob a perspectiva das culturas camponesas (González, 2020), promete liberação e autonomia (modernidade, enfim), mas, na prática, funciona como violência e regulação: colonização cultural (colonialidade), como diria Paulo Freire (2019), e alienação (Fanon, 2020). Parte da limpeza do espaço - que caminha também através de expulsão econômica e expropriação do território - é realizada pelo convencimento de que o futuro está na cidade e no mundo moderno e urbano. Gostaria de deixar claro que, neste texto, enfatizo as contradições que o processo produz na vida prática, assumindo exemplos pessoais que são os que posso oferecer agora.

${ }^{5}$ Lia muita literatura e ensaio, que ajudaram a suportar o deslocamento que sentia dentro da universidade. Eram, contudo, algo localizado à parte ou abaixo dos discursos científicos e, por isso, considerados "menores".
} 
A universidade formou-me para ocupar esse lugar de exterioridade em relação aos conhecimentos do Sul. Como professor, eu reproduzi, durante anos, esse exclusivismo epistêmico entre estudantes, mesmo trabalhando no norte do Tocantins.

Com o tempo, fui percebendo a esquizofrenia que os sujeitos universitários vivem: somos vítimas de um segundo nível do exclusivismo. Apregoamos que os sujeitos do Norte são, dentro da divisão científica, aqueles que detêm o exclusivismo teórico, afirmamo-nos como os únicos que no Sul, ao aplicar essas teorias, produzem conhecimento reconhecível como tal. Assim, reforçamos os sujeitos do Norte como produtores da camada mais sofisticada do saber, a teoria. Por outro lado, de dentro do Sul, mentalmente nos posicionamos e ensinamos a nossos alunos posicionarem-se fora, orientando-os a construírem a si mesmos, por serem universitários, como os únicos sujeitos epistêmicos - mesmo que parcializados - no Sul.

Por esse motivo, o “descobrir” autores, autoras e autorias do Sul é aceitar um gesto de despersonalização, sair de nós e, à instância de outros, andar por aí a descobrir-nos. Trata-se de fenômeno conhecido: Dom Pedro Casaldáliga a tempo convida-nos fazer coincidir nossa cabeça com o lugar em que nossos pés pisam ${ }^{6}$. Em meu caso, sinto que os meus pés foram sendo alienados desse chão pela escolarização. Desde 2014, tento, com certo tremor, fincá-los. É que esse chão esteve, desde muito, em chamas - é um chão violentado, explorado, dominado e encoberto - do qual assepsia historiográfica ensinou-me a me distanciar.

Diria, hoje, depois de reencontrar-me com as areias e argilas do Cerrado Amazônico, seus povos e suas lutas, que é preciso, pois, um gesto duplo. Primeiro, necessitamos desencobrir-nos por meio da abertura dos olhos, de dentro para fora, e, em seguida, tirar o véu que está posto sobre as teorias do Sul. Isso só é possível ao reconhecermos nossa humanidade por inteiro e ao nos assumirmos como sujeitos e sujeitas epistêmicos/as que somos: reconhecer as comunidades de vida (DUSSEL, 2020), existência e de r'existência onde viemos e, por fim, compreender que não estamos sós, que diversos outros trabalharam antes de nós.

$\mathrm{Na}$ assunção da solidariedade horizontal e vertical, trata-se de assumir que pronunciamos a palavra como resposta à vida, a esse chão que nos chama a denunciar a colonização como passado-estendido, e proclamar um agora forte, liberado.

\section{A economia (afetiva e) política do conhecimento}

6 Foi da Valéria Santos, agente da Comissão Pastoral da Terra Araguaia/Tocantins, que ouvi esse aforismo pela primeira vez. Depois, soube que ele surgiu como um enunciado forte da teologia da libertação e é atribuído a Dom Pedro Casaldáliga. 
Demorei para pisar o abigarrado chão camponês, americano e ameríndio da realidade brasileira (RAMOS, 2019). Esse retorno foi mediado por diversos encontros. Era desafiado evidenciar os ganhos práticos e políticos de minha presença em campo tanto pelos ribeirinhos quanto por agentes pastorais. Muitos deles, como Maria da Ilha e Gedean, deixaram claro que o saber deve servir à luta pelo território e modo de vida. Valéria Santos, agente da Comissão Pastoral da Terra, passou uma tarde questionando, para mim, a isenção da instituição em que trabalho sobre o despojo territorial que ocorria, e que desde então se intensificou, ao meu/nosso redor.

Por outro lado, mesmo cobrando posicionamento, não deixaram de partilhar suas histórias de vida, os saberes da vida e da luta. A realidade do saber produzido nesse diálogo, na partilha da palavra, com aqueles sujeitos e sujeitas não referendava as biogeografias da razão (RAMOS, 2019) que me 'norteavam'7.

Não encontrei melhor fundamento para esse norteamento que uma narrativa de Silvia Rivera Cusicanqui (2018), em uma palestra no México. Ela pede, durante as oficinas de sociologia da imagem, que os presentes fechem os olhos e imaginem o Ocidente: eles direcionam a sua mente para a Europa. Porém, estando na Améfrica Ladina (GONZALEZ, 2018), o Ocidente é a China, o Japão etc. A nossa cabeça habita uma geografia, os pés, outra; pés no Sul, a cabeça é norteada.

A denúncia do norteamento do pensamento chegou ao universo teórico através de dois conceitos, com os quais entrei em contato em diferentes tempos: com geopolítica do conhecimento, desenvolvido por Enrique Dussel, em 2014; e com geografias da razão, em 2017, quando li/vi ${ }^{8}$ Lewis R. Gordon. Mesmo diferentes, ajudaram-me na compreensão das relações entre o colonialismo e a epistemologia. A episteme norte-atlântica, uma resposta do Norte a problemas locais, foi, em conexão com o colonialismo econômico e político, instituída como saber único sobre a realidade, que foi unificada em uma totalidade: história universal, globo etc.

\footnotetext{
7 Devo metáfora-conceito 'nortear' a Alex Ratts. Ele falou-nos dela durante o curso Epistemologias Africanas e Indigenas, oferecido na UFT/Araguaína.

8 Assisti diversas "performances" teóricas de Gordon no YouTube. Elas ajudaram-me a conhecer os textos e as ideias. As mais esclarecedoras delas - e também faladas em "friendly English" - são Gordon (2015) e Gordon (2019, 2019). Chamo-as de performances tendo em mente Portelli (2016) que a afirma "a oralidade não gera textos, gera performances," um discurso em processo e em diálogo, no qual a corporeidade, o ritmo, a entonação são, também, contéudos e não apenas meios. Essas "performances" tanto de Gordon como de Cusicanqui parece-me que evidenciam o que Santos (2018) chama de razão aquecida pelo corpo e pelo que Escobar (2014) chama de sentirpensar.
} 
A norteação, assim, é a manifestação do encobrimento - quando não a destruição - das epistemes ameríndias e amefricanas ${ }^{9}$, também entendida como cegueira epistêmica (MIGNOLO, 2002): não olhamos e não enxergamos a nós mesmos e a esses outros que vieram antes - e junto de nós, homens e mulheres do Sul - como produtores de saber.

À raiz das lutas por descolonização na África, Ásia e Caribe, de 1960 em diante, interpelações do Sul emergiram no cenário acadêmico. Essas interpelações, consideradas ideias, são as dos intelectuais letrados. Além disso, como já falei acima, também encobre autorias orais, visuais-corporais e ritualísticas-religiosas. No entanto, à raiz da colonização histórica, os povos não interromperam o trabalho do pensamento (GORDON, 2015); fizeram foi conectá-lo à r'existência (PORTO-GONÇALVES, 2019).

Dois grupos letrados, certificados no Norte, deram início à crítica das relações entre colonização, cultura e episteme. Apenas um deles, contudo, dirige-se à colonização como passado-estendido. Acompanho-os há tempos e suas obras foram, durante longo período, lugares para respirar - e nos quais inspirar-me. Antes de encontrá-los, o espaço de leveza era a antropologia cultural. Através de Todorov, com o qual entrei em contato no primeiro ano do curso, em 1998, ouvi falar da alteridade. Sem tardar, entendi que isso tinha a ver comigo. A descrição densa de Geertz, a prática de ver o outro e procurar entendê-lo a partir de seus próprios termos, isso pareceu a coisa certa a fazer.

Em 2001, fui apresentado aos textos de Edward Said e Homi K. Bhabha. Numa aula de Monografia, Olga Cabrera escreveu Cultura e imperialismo (1995) na lousa verde e disse que seu autor era pós-colonial. Fui à biblioteca do campus da minha universidade e peguei emprestado o livro cuja leitura eu gostava de mostrar nos corredores. Era empolgante a denúncia da relação entre as narrativas ficcionais e científicas europeias sobre as áreas coloniais. Além disso, eram observadas as respostas, as narrativas de resistência à dominação cultural e política escritas por intelectuais africanos, asiáticos e, também, caribenhos. O mais visceral deles, para mim, era Salman Rushidie, de quem li Versos Santânicos e Os filhos da meia-noite; também li V. S. Naipaul, Maryse Condé, Arundhai Roy, Ngũgĩ Wa Thiong’o etc.

Uma amiga emprestou-me para sempre o Local da cultura (2001), de Homi K. Bhabha (2001). A crítica ao essencialismo cultural e ao apagamento das vozes subalternas fez desse autor, junto com o Said, o interlocutor de minha jornada no mestrado e doutorado. Do ponto de vista do método, tentava ajustar a descrição densa a obras literárias. É assim, ao menos, que leio aqueles textos. 
Eu vi em Bhabha e Said que intelectuais do Sul podiam teorizar e, mais que isso, se dar bem ao fazê-lo. Na tese, então, aventurei-me a exercer a criatividade teórica, conectada a certa postura desafiante às estruturas disciplinares, de modo especial, à historiografia brasileira, algo que aprendi com Olga Cabrera, minha orientadora de toda a vida.

Duas anedotas mostram bem o lugar dos pós-coloniais dentro da universidade. Na banca de doutorado, uma arguidora considerou um erro eu não citar Roger Chartier ${ }^{10}$. O autor deveria estar presente na versão final da tese, o que eu fiz. Said e Bhabha, talvez, não fossem para ela teóricos da cultura; no máximo, quiçá, bibliografia de apoio. Um dia, falava empolgado dos pós-coloniais e uma amiga disse que "eu falava de livros que apenas eu conhecia”. Ela estava certa. Acreditava, então, que todos conheciam Said e Bhabha, mas era mentira. Na UFG, éramos poucos, e todos orientados por Olga Cabrera.

O que se chamou de $O$ pós-colonial envolve mais gente que aqueles que li. Acessei obras que são uma resposta às críticas sofridas desde 1978, quando Said publicou Orientalismo: A invenção do Oriente pelo Ocidente, tido como a obra inaugural do pensamento pós-colonial. Dirlik (1994) refere-se à ênfase em aspectos culturais em detrimento dos econômicos e políticos do imperialismo. Para mim, contudo, essa crítica marxista não fazia sentido. A minha formação universitária poderia ser nominada como "o esforço para afastar as crianças do materialismo histórico-dialético". Dentro do culto à História cultural que havia então, o pós-colonial entrara: uma forma de fazer História em diálogo com autores do Sul. Isso tudo interessava porque era preciso questionar o olhar imperial sobre o outro; este com quem eu, desde sempre, sentira estar $^{11}$.

O pós-colonial aparece, ainda, como uma reflexão sobre o período histórico posterior à descolonização da África, Ásia e partes do Caribe. Portanto, para muitos, era um período. Assim, mesmo que Homi K. Bhabha tenha investido contra a ideia de que haveria um hiato histórico provocado pelas independências, autores como Kwame A. Appiah (1992) também dão esse uso ao termo, e era assim que eu também o usava. Parecia politicamente importante destacar a independência das antigas colônias. O pós-colonial era um signo de articulação entre teoria e independência política.

Não lidava com o pós-colonial como um rótulo criado dentro das universidades norteatlânticas por Edward Said, Homi K. Bhabha, Stuart Hall, que eram nascidos, respectivamente,

10 O historiador francês Roger Chartier e o livro A história cultural: entre prática e representações era, com Carlo Ginzburg, o núcleo do cânone da História cultural durante os anos de minha formação.

11 Quando eu entrei em contato com a autobiografia de Said, Fora de lugar, a identificação foi automática. As críticas que ele recebera em relação ao texto, para mim, eram, e ainda são motivadas pelo enfrentamento do mainstream político norte-atlântico e à sua militância pela causa palestina. 
na Palestina, Índia e Jamaica, ocupando quadros universitários no Norte. Essa geopolítica não entrava em minha conta ainda.

Quando entrei na UFT, em 2009, eu trabalhei, com Márcio Melo, alguns autores póscoloniais africanos, entre eles Appiah e Wa Thiongo. Mas, em 2011, trabalhando com Luiza Silva, reencontrei-me com a colonialidade do poder através de um artigo de Walter Mignolo sobre Silvia Rivera Cusicanqui e História Oral. Allysson García falava-me de colonialidade do poder desde 2002. No entanto, eu não via a utilidade de Quijano para o que eu queria fazer. A disciplina trabalhava uma epistemologia materialista e, depois de passar 10 anos na universidade sem ler mais que o Manifesto do Partido Comunista, estava estudando e ensinando ideologia, quando lera, e gostara, dos textos de Althusser. Essa parceria, ainda, permitiu a reaproximação com a História oral e com sujeitos tocantinenses.

Por volta de 2013, tentei aplicar a epistemologia pós-colonial a narrativas sobre a região do Sul do Pará, de onde saíra em 1998, e norte do Tocantins, para onde voltara em 2009. Havia o fato de que eu estava aqui e isso tornava essas narrativas, para mim, por mais interessantes que fossem, superficiais ${ }^{12}$. As narrativas dos sujeitos daqui eram infinitamente mais potentes para dizer-me o que é este lugar. Nesse sentido, li a obra de Mignolo (2003) como uma resposta latino-americana à Said. Retive, contudo, a discussão sobre epistemologia e semiose colonial (MIGNOLO, 2003).

No início de 2014, convidado a pesquisar os impactos das barragens hidroelétricas em comunidades ribeirinhas, comecei o processo de aproximar-me do chão norte-tocantinense. Tentei articular a descrição densa (GEERTZ, 1989) e a História Oral (THOMPSON, 1992), mas os encontros (RAMOS, 2019) pelos quais passei colocaram em xeque a ideia de cultura e a fetichização do método (GORDON, 2008, 2013) que colocava sobre o terreno. Esses encontros envolveram epistemólogos ribeirinhos - homens e mulheres - que deslocaram as biogeografias da razão postas sobre o terreno. Estando com eles, lado a lado, perguntava-me: o conhecimento que essas pessoas partilhavam poderia ser entendido apenas como "representações"13? Seriam representações que eu, a partir do método, transformaria em conhecimento? Era correto tratar esses sujeitos e seus conhecimentos desse modo? Não eram

12 Durante esse tempo pesquisei a obra de Adriana Lisboa (Azul corvo) e as narrativas jornalísticas, como $O$ nome da morte, de Klesver Calvacanti. Também escrevi sobre as ideias e viagens de Percy H. Fawcett no Xingu.

${ }^{13}$ A discussão da História cultural sobre representação é longa, mas, em geral, fala dos significados que são tomados como realidade. Essas representações, quando criticadas e submetidas ao método, ajudam a conhecer as percepções sobre o real, e não o real. Certos sujeitos representam o real, certos sujeitos fazem a crítica dessas representações e, por isso, aproximam-se mais de um conhecimento do real. 
esses sujeitos vítimas da relação entre geografia e razão? Não havia uma questão racial, de gênero e de corpo, colocada?

Para entender o norte-tocantinense e as questões que a minha inserção nessa geopolítica levantaram, fui encontrando em categorias como colonialidade do poder, do ser e do saber um mapa com o qual me orientar, conhecer a realidade e o lugar de um pesquisador universitário dentro dela. Enfim, pensar como as narrativas construíram certa geografia ${ }^{14}$ fascina se você está longe ou posiciona-se fora. De "dentro" de estatuto (RAMOS, 2019) e articulavam-se à violência, ao despojamento espaço-territorial, ao patriarcado e, de modo especial, ao colonialismo como passado-presente ${ }^{16}$.

Enfim, com os dois grupos letrados, pós-coloniais ${ }^{17}$ e descoloniais ${ }^{18}$, aprendi que intelectuais do Sul podiam teorizar e, mais que isso, deveriam fazê-lo. Deveriam desencobrirse.

Entre fins de 2018 e início de 2019, estive afastado do país e de meu trabalho. Quando retornei, qual foi o susto: todos na Universidade eram decoloniais ou pós-colonial e decolonial a la $v e z^{19}$. De imediato, pareceu-me um avanço, afinal, a universidade, desde 2015, quando da

14 Pensando aqui no argumento de Said (1995).

$15 \mathrm{O}$ que gostaria de deixar claro é que a crítica de Said e outros às narrativas imperiais e eurocêntricas é fundamental, mas deve ser, também, entendida como conectada à localização institucional. É uma crítica feita de dentro do Norte e tem algumas de suas raízes no Sul.

16 Durante essas experiências de contato com sujeitos expropriados de seus territórios no ano de 2014, a senadora Kátia Abreu (mandato correspondente na época aos anos de 2007-2014) repetia quase textualmente argumentos de pensamento do período colonial ao atacar os grupos indígenas e a posse, por parte deles, de seus territórios.

17 Para Castro Gomes (2005, p. 39), os pós-coloniais estão concentrados "en una crítica cultural de la colonialidad, descuidando el análisis de sus condicionamientos materiales, es decir, del colonialismo".

${ }^{18}$ Para uma versão da discussão entre entre descolonial e decolonial ver MOUJAN, SILVA \& RAMOS (2020, p. 13). Afirmamos ali: "existem implicações políticas na escolha do termo decolonial ou descolonial. (...) cientes das respectivas cargas teóricas/históricas e respeitando a própria formação em seu emprego. Em ambos os contextos e usos, há um enfrentamento latente, uma crítica sobre os lugares, formas de produzir e validar conhecimentos, além das tentativas de tensionar esses cânones. Daí escolhermos o fazer pedagógico de(s)colonial (...) que aproxima as duas categorias por seus objetivos: a desconfiança com o modelo ilustrado/positivista e colonial/neocolonial, na América Latina, Caribe e África." Considero que pensamento descolonial, as ideias descolonizadoras, articuladas à práticas descolonizadora de movimentos sociais e políticos do Sul, especialmente América Latina, Caribe, África e Ásia. Por Decolonial entendo a versão dessa discussão sistematizada por autores do Sul nas universidades norte-americanas e europeias a partir do conceito de colonialidade do poder de Anibal Quijano. Por mais que exista intercâmbios e uma enorme coerência entre o descolonial e o decolonial, acredito que é preciso dimensionar o pensamento descolonizador produzido no Sul e o produzido nas universidades do Norte.

${ }^{19} \mathrm{Um}$ diálogo coletado nas redes sociais exemplifica o incômodo semelhante. Um professor argentino que vive no Brasil afirma: "Estou lembando da época em que falar de uma 'filósofo latino-americano' era ser alvo de piada e exclusão. Hoje vejo com surpresa que aquelas mesmas pessoas excludentes falam em decolonialismo, filosofia africana, filosofia feminista, lugar de fala, e sei lá quantas coisas... Será possível uma mudança radical de pensamento na academia ou será apenas uma moda como foi a filosofia popular, o existencialismo, a posmodernidade e tantos outros?" Alguém, da rede de contato dele, responde: "Ao passar pelo filtro das acadêmicas do norte, o latino-americano perdeu referências aos processos políticos e populares anti-coloniais de fato (ex. independências do séc XIX, 'terceiro mundo', Bandung etc que agora viraram os feitos sujos e maus do 'populismo.' Por isso, pode virar moda, como a camiseta do Che". Para aqueles que estão dentro da universidade 
institucionalização das cotas étnico-raciais e econômicas, mudou decisivamente. Sujeitos historicamente excluídos começaram a ocupar o espaço. Através de coletivos, movimentos sociais e da ascensão individual, posicionam-se dentro das instituições a ponto de pautar, ao menos parte, o debate teórico.

Mas não eram apenas esses os decoloniais. Diversos sujeitos que habitam a universidade há mais tempo encontraram no decolonial uma perspectiva teórica que ajuda a politizar sua prática.

E ainda não eram apenas esses. Havia e há os que assumem o decolonial como uma mercadoria acadêmica de prestígio, afinal, Quijano, Maldonado-Torres, Grosfoguel, Lugones etc. chegam aos campi universitários brasileiros a partir de grandes centros universitários dos Estados Unidos. Depois do Ciência Sem Fronteiras ${ }^{20}$, muita gente descobriu-se descolonial no Norte através da descoberta de autores e autorias do Sul. Esses grupos são notáveis pela capacidade de expropriação epistêmica (SMITH, 2018), pela formalização e esfriamento de ideias que surgiram em contextos quentes - o das lutas sociais. Foi o que ocorreu com o póscolonial, há 10 anos.

Cusicanqui (2010) afirma que Mignolo e Walsh produzem uma versão logocêntrica e nominalista da descolonização e que, por meio de redes de clientelismo acadêmico, acabam por encobrir as autorias enraizadas nas lutas sociais. Falando a partir do capital cultural legitimado por instituições como Duke University, Universidade California, Rugters University, University of North Carolina, Binghamton University etc., e distantes das lutas reais do Sul, a decolonialidade pode se tornar uma gramática teórica formal e fria: trabalho morto a ser transferido de mercadoria-textos em textos-mercadoria ${ }^{21}$.

Devemos reconhecer, contudo, que o descolonial é a objetivação do trabalho realizado por gerações de sujeitos e sujeitas que construíram a r'existência em diversos contextos sociais do Sul. Em um texto acadêmico, uma forma e fazer isso é, em geral, o trabalho da citação. Quijano, contudo, cita pouco e referencia menos ainda. Se enunciados teóricos aparecem descolados desse trabalho, estabeleceremos com eles uma relação fetichizada, os quais perderão

brasileira e que, desde muito estiveram conectados a discussão latino-americana e africana, do Sul, a emergência decolonial parece um modismo. Ou, na minha opinião, corre o perigo de transformar-se em um.

${ }^{20}$ O CSF - Ciências Sem Fronteiras foi "é um programa que busca promover a consolidação, expansão e internacionalização da ciência e tecnologia, da inovação e da competitividade brasileira por meio do intercâmbio e da mobilidade internacional" criado pelo governo de Dilma Rouseff em 2011 e extinto em 2017 no governo Michel Temer. Ele forneceu cerca de 100 mil bolsas de estudos para formação de estudantes brasileiros no exterior. Disponível em www.cienciasemfronteiras.gov.br Acessado em 10 de agosto de 2020.

21Penso no produtivismo acadêmico. Em suas várias versões, ele institui a alta produtividade como escala da produção de produtos acadêmicos, trazendo uma lógica de mercantilizando para a produção do pensamento. 
a sua potência por desenraizamento. Devemos nos cuidar para não os fetichizar, tomando-os como mercadorias acadêmicas de prestígio.

O perigo que ronda os descoloniais é o do desenraizamento "na produção", e da fetichização "na reprodução". Para avançar no desenvolvimento desses enunciados, é preciso reconectá-los ao trabalho social realizado por gerações de pensadores, comunidades e movimentos sociais descolonizadores.

É preciso, pois, lutar para que as teorias do Sul não se alienem das comunidades de vida, existência e r'existência, e se formalizem como uma nova ortodoxia que sirva aos rituais iniciáticos dos templos acadêmicos - no Norte e Sul. A sua chegada às universidades deve significar a desnorteação das universidades e sua inserção nos problemas reais das comunidades de luta Sul. Se isso não ocorrer, será a decadência ${ }^{22}$ da decolonialidade enquanto conjunto de enunciados teóricos e uma derrota para todos que vemos nela mapas teóricos com os quais nos orientarmos.

Por fim, para evitarmos os problemas indicados acima, devemos:

a) Trazer para dentro dos campi o trabalho vivo do pensamento feito agora: pelos movimentos sociais, coletivos, comunidades, pelos epistemólogos da vida real, para el llano en llamas que o Sistema Mundo Moderno Colonial, desde 1492, transformou o Sul, ao encobri-lo. É hora, pois, de desencobrir-nos e desencobrir a todos.

b) Fortalecer, dentro dos campi, o contato com o trabalho social necessário à construção do decolonial através da abertura e do estudo sistemático do arquivo teórico do $\mathrm{Sul}^{23}$ : Darcy Ribeiro, Lélia Gonzalez, Sueli Carneiro, Paulo Freire, Celso Furtado, González Casanova, Fals Borda, Raúl Prebisch, Abdias Nascimento, Enrique Dussel, Aimé Cesaire, C. L. R James, Eric Willians, Gustavo Gutiérrez, Eduoard Glissant, Wilson Harris, Gloria Alzandua, Ailton Krenak, David Kopenawa, Antonio Bispo dos Santos, Paget Henry, Guerreiro Ramos, Jose Maria Mariategui, Frantz Fanon, Silvia Rivera Cusicanqui etc.

\section{Deslocar geografias da razão e pensar memorioso}

22 Penso aqui no conceito de decadência disciplinar de Lewis R. Gordon (2013): ossificação, formalização estremada e autorreferenciação.

${ }^{23}$ Existe um medo de que os arquivos sejam incendiados e que os textos sejam destruídos. A imagem que vem em minha cabeça sobre os arquivos do Sul é de que eles sempre estão queimando-se de dentro para fora. Ao arquivo, na verdade, vamos em busca de fogo materializado no trabalho dos antepassados. 
Dois autores parecem ajudar os de dentro da universidade a reconectar-nos ao pensamento e à práxis descolonizadora, objetivado autorias escritas e orais, em ação política e performances artísticas: são Frantz Fanon e Silvia Rivera Cusicanqui.

\section{Aproximações de Frantz Fanon ou como deslocar as biogeografias da razão}

No Centro de Estudos do Caribe (CECAB-UFG), onde estudei entre 2000 e 2009, líamos Glissant e Harris, mas eludíamos Fanon. Olga Cabrera, com quem trabalhava, é crítica da forma que a mulher aparece em Pele branca, máscaras negras. Em 2006, porém, Fanon emergiu como o teórico da luta de libertação nacional africana e, recentemente, descobri que essa foi uma das formas da recepção dele no Brasil (FAUSTINO, 2018). Foi quando fazia um curso de formação em História da África, na Universidade Estadual de Goiás. Em 2011, reli Os condenados da terra com o professor Márcio Melo em um curso sobre Literatura e identidade nacional na África (RAMOS; MELO, 2011).

Em 27 de abril de 2017, contudo, Luiza Silva ${ }^{24}$ enviou-me uma mensagem. Dizia que eu deveria ler Lewis R. Gordon e enviou, em anexo, um artigo intitulado African- American Philosophy, Race and the Geography of Reason (GORDON, Lewis R. In: GORDON; GORDON, 2006) e a indicação de What Fanon Said: a philosophical introduction to his life and tought, explicando que Gordon era um filósofo negro jamaicano, "gente do bem" 25 , e que uma amiga ${ }^{26}$ e estimulara-a a conhecer sua obra. No mesmo dia, fiz buscar na internet e, como, como de costume, antes de passar aos textos, vi alguns vídeos. ${ }^{27}$ Ele participara da organização de um livro sobre ${ }^{28}$ Paget Henry (2000), cujo Caliban`s reason: introducing Afro-Caribbean philosophy eu li em 2004 com Olga Cabrera. Também comecei a reler Sartre, sobre quem eu nutria curiosidade desde que havia lido seus romances e contos, e Fanon. Fiquei cerca de 5 meses, pelo prazer de aprender com um sujeito que parecia tão simpático ${ }^{29}$, fuçando ${ }^{30}$ textos e

\footnotetext{
${ }^{24}$ Refiro-me à professora doutora Luiza Helena Oliveira da Silva, semioticista e professora da Universidade Federal do Tocantins, Campus de Araguaína. http://buscatextual.cnpq.br/buscatextual/visualizacv.do?id=K4771397Z6

${ }^{25}$ Em nosso vocabulário, quer dizer progressista e posicionado ao lado, diríamos hoje, dos condenados da terra.

${ }^{26}$ A amiga é a Profa. Dra. Rosemere Ferreira da Silva, docente da Universidade do Estado da Bahia (UNEB). Lattes: http://lattes.cnpq.br/5573907563872708

${ }^{27}$ GORDON, Lewis R. "Decolonizing knowlegde - norms, methods, and disciplinary decadence”. Disponível em https://www.youtube.com/watch?v=-fsJnqdIFTE\&t=2483s.

${ }^{28}$ GORDON, Lewis R.; Gordon, Jane Anna at all. Journeys in Caribbean Thought: the Paget Henry reader. New York/London: Rowman \& Littefield, 2016.

${ }^{29}$ Assim como as de Silvia Rivera Cusicanqui, as performances de Gordon são muito corporais e rítmicas. Esse pensar com o corpo, desde que vi, atrai muito minha atenção.

${ }^{30}$ Fuçar é procedimento de experimentação pedagógico, como mostra Silva (2015).
} 
vídeos, sentindo as ideias e tentando encontrar laços e pertinência entre minhas angústias teóricas e o que Gordon dizia.

Ao participar de evento de História oral, em Manaus, fui informado, de última hora, que teria que fazer uma palestra, pois um dos colegas avisou que não compareceria, e cabia a mim substituí-lo na mesa-redonda. Katia Cilene do Couto, a organizadora, pediu-me que o substituísse, e a maneira que encontrei foi apresentar experiências com epistemólogos ribeirinhos $^{31}$ que não aceitavam as biogeografias da razão. Nessa apresentação, fiz uma autorreflexão sobre a pesquisa de campo, na qual eu havia fetichizado o método. Usei ainda o termo cegueira epistêmica de Walter Mignolo (2000). Através da leitura de Silvia Rivera Cusicanqui (2010) e de sua crítica às metodologias extrativas ${ }^{32}$, assumi que o conhecimento produzido durante as entrevistas é coprodução, pois constituía-se como fruto de encontro e diálogo entre sujeitos e epistemologias (RAMOS, 2019). Penso que conseguira traduzir em termos teóricos experiências "quentes" 33 , que conectavam luta social, pensamento e produção de conhecimento.

Essas leituras articularam-se, ainda, à preocupação de não fetichizar o decolonial. Por isso, resolvemos, Sariza Caetano Venâncio e eu, pautar no GEHCULT ${ }^{34}$ autores que pensaram e escreveram em conjunto com as comunidades de vida, existência e r'existências do Sul. São autorias quentes que dialogavam em seu trabalho novo do pensamento com o trabalho do pensamento feito por gerações anteriores e por movimentos políticos nos quais se engaja(ra)m. Começamos por Fanon ${ }^{35}$ e Paulo Freire, mas a proposta era ler bell hooks, Enrique Dussel, Raúl Prebisch e Celso Furtado, Silvia Rivera Cusicanqui, Lélia Gonzalez e Sueli Carneiro.

As sessões sobre Fanon atraíram em média 35 pessoas, entre estudantes, ativistas e outros, em cada sábado do primeiro semestre de 2019. Organizados como roda de conversa,

\footnotetext{
${ }^{31}$ Esses sujeitos, que habitavam há 4 ou 5 gerações a Ilha de São José, haviam sido deslocados pela UHE de Estreito, construída no Rio Tocantins. Eles articulavam a história de luta pela Ilha, que passou por diversos momentos, com os saberes relacionados ao enfrentamento à Usina.

${ }^{32}$ Conforme mostrei em Ramos (2019), ouvi de diversos ribeirinhos a crítica quanto ao fato de que a universidade e os pesquisadores vão às comunidades, "pegam" as histórias e nunca devolvem nada, nem informam àqueles com quem conversaram sobre os destinos dados ao material. A crítica mais contundente foi de um pescador, Valdeci, que disse estar cansado de dar entrevista para "essa gente que vem aí gravar isso tudo e leva, e ninguém nunca sabe o que eles fazem". Essa entrevista fora realizada, por mim, em janeiro de 2015.

${ }^{33}$ Penso aqui o termo quente no sentido que dá Boaventura de Sousa Santos (2018, p. 175) dá a ideia de "aquecer os conceitos" a partir da "indignação ativa." Mas também no sentido de Marx (2017) quando fala que o trabalho vivo, em um ato prometéico [que relacionaria a Ogun e não à divindade grega], transforma traz a vida, incorpora, através do trabalho novo, o trabalho morto, no processo de produção.

${ }^{34}$ GEHCULT - Grupo de Estudos de História e Cultura é o grupo de estudos que, desde 2013, reúne-se duas vezes ao mês para ler e debater sobre teorias contemporâneas, especialmente as do Sul. Ele é um projeto de extensão vinculado ao curso de História e ao Programa de Pós-graduação em Estudos de Cultura e Território da UFT de Araguaína e objetiva construir interlocuções entre a universidade e sujeitos da sociedade local interessados em conhecer a universidade ou a ela retornar para fazer mestrado ou doutorado.

${ }^{35}$ Escrevo esta página no dia que Fanon completaria 95 anos.
} 
conversamos a respeito de Pele negras, máscaras brancas (2008) e Condenados da terra $(2005)^{36}$, sobre as zonas de não ser, violência, a alienação colonial e dominação psíquica ${ }^{37}$. Como o grupo é aberto, a conversa busca conectar teoria e a vida - os testemunhos e anedotas pessoais são bem-vindos, desde que articulados à teoria. Notória foi a discussão sobre embranquecimento como pressuposto para a humanização - e, claro, todo o resto: eurocentrarse, modernizar-se e demais signos da brancura. Debatemos, ainda, a mentira por trás dessa promessa: por mais que um condenado embranqueça, posicione de forma eurocentrada e modernize, não adianta; por mais que ele fique bom na episteme ocidental, nunca será o suficiente. Sua existência enquanto negro virá antes; a relação colonial e o racismo que a justificam é a violência em estado bruto.

A compreensão, por parte dos presentes que usaram a palavra, da relação entre teoria e engajamento político que permeia obra e vida de Fanon como médico e militante político na Argélia foi marcante. Parecia haver entre os presentes um desejo de não apenas pensar, estudar, ler, escrever, mas de agir, colocar o corpo no palco do saber. Para mim, essa instituição do lugar do corpo aliou-se, quiçá, à proposta de deslocar as geografias da razão. A crítica de Fanon que aprendi lendo Gordon (2015) -, sobre a razão nunca estar onde o homem negro está, é algo poderoso e libertador. Articulando corpo e geografia da razão, passei a usar o termo biogeografias da razão (RAMOS, 2019).

$\mathrm{Na}$ prática, o que encontro entre os movimentos sociais e as lutas políticas das comunidades é o deslocamento das biogeografias da razão. Nos contextos de luta desses sujeitos e sujeitas, a humanidade não está reduzida à brancura e à razão; ali, parece-me, todos afirmamse como humanos por inteiro - razão, emoção e corpo - e, por isso, sujeitos de sua história e liberação. Como diz Carolina Motoki (2020), referindo-se ao Movimento Teia no Maranhão, “os que mais estão sofrendo com a violência do capital estão batendo tambor, erguendo os maracás, dançando, cantando 'na lei ou na marra nós vamos ganhar"”. A práxis descolonial é um processo que atravessa, em um nível, corpo, razão e emoção, e, em outro, economia, política e território.

As leituras, de Gordon e Fanon, ajudaram-me a deslocar as geografias da razão, avançar na crítica ao exclusivismo epistêmico e reconhecer as pessoas com as quais eu partilhava aqueles momentos como sujeitos epistêmicos - e, ao reconhecê-las e as suas autorias orais, reconhecer-me e as autorias escritas do Sul. Em nível pessoal mais pessoal ainda, uma complexa

\footnotetext{
${ }^{36}$ Naquele momento, eram as obras de Fanon disponíveis em Língua Portuguesa e publicados no Brasil.

37 Tivemos a sorte de ter conosco o Robenilson Barreto, psicanalista negro, leitor de Fanon, que nos ajudou a conversar sobre dominação psíquica e alienação colonial.
} 
reconciliação com o mundo rural de onde havia saído aos 06 anos de idade se iniciara em 2014, tornada possível a partir do engajamento político com os movimentos sociais e as comunidades camponesas e quilombolas ${ }^{38}$; começava a receber racionalização. A isso tenho chamando de abrir os olhos por dentro, em nível individual; em nível institucional, chamo essa lógica de desencobrir o Sul teórico e desnortear as universidades do Sul.

\section{Silvia Rivera Cusicanqui - o pensar memorioso}

Em março de 2016, conheci a Carolina Motoki. Ela acabara de retornar da Bolívia e estava, assim como eu, observando a discussão sobre o bem-viver e o biocentrismo ${ }^{39}$ andino, inserida na constituição do país. Em um momento de formação na Comissão Pastoral da Terra, em 06 de agosto, eu, Valéria Santos, Carolina Motoki e Felipe Oliveira discutimos a possibilidade de discernir, nas epistemologias dos movimentos e comunidades, categorias e conceitos que, à semelhança do "buen-vivir", fossem pano de fundo de sua resistência: a categoria "vida boa" emergiu na discussão. Tempos depois, no carnaval de 2017, Felipe Oliveira contou que na Comunidade Taboca usava-se, além de "vida boa", "vida boa e sossego".

O exercício de discernir essas categorias encontrava respaldo na discussão do Bem Viver, mas também em Silvia Rivera Cusicanqui, na sua proposta de "recuperación de una episteme índia" e de diálogo com conceitos-metáforas indígenas como chi 'ixi e pachacuti. Para nós e para ela, esse processo é o da vitalização do pensamento e das autorias orais pensadas não como sobrevivências do passado, mas como parte do trabalho vivo do pensamento e da r'existência dentro das lutas pela descolonização dos territórios e dos modos de vida.

Por estar lendo e vendo "performances" de Cusicanqui desde 2014, em Manaus, em setembro de 2017, falei de suas críticas ao extrativismo epistêmico e propus o reconhecimento do conhecimento produzido durantes as entrevistas de História Oral como fruto de encontros epistêmicos (RAMOS, 2019), e não de exclusivismo, ao qual me referi acima. Por esse motivo, acredito que o diálogo com a autora, assim como com Fanon, é fundamental para o enraizamento do descolonial no trabalho social do pensamento e da práxis descolonizadora.

\footnotetext{
${ }^{38}$ Uma dessas parcerias é o Neuza-UFT, que teve início em 2018. Trata-se de um núcleo que pretende articular conhecimento agrícola camponês e quilombola com os saberes acadêmicos de modo a (re)construir realidades que ajudem as comunidades no enfrentamento aos processos de despojo territorial que, atualmente, as ameaçam. $\mathrm{O}$ Núcleo é uma parceira entre UFT e Comissão Pastoral da Terra.

${ }^{39}$ Um pouco antes, em 2014, comecei um diálogo com Elson Santos Silva sobre perspectiva biocêntrica e ecopedagogia através da orientação de sua tese de doutorado. Estimulei-o a ler os decoloniais e a Cusicanqui. Em decorrência disso, comecei a lê-la de novo, o que eu não fazia desde 2011, quando ouvi falar dela através de um texto de Walter Mignolo (2002).
} 
A trajetória de Silvia Rivera Cusicanqui, mulher chi'ixi, está marcada por sua militância junto aos movimentos aymara bolivianos. Em 1984, juntamente com estudantes aymara, funda o Taller Andino de História Oral (THOA) ${ }^{40}$ e organiza pesquisas com as comunidades indígenas sobre a memória dos levantes katarista em 1930. Por meio de entrevistas, rodas de conversa, são registradas as memórias desses eventos sob um ponto de vista das comunidades indígenas. Depois, através de teatro de rua e telenovelas, o Taller ajuda a vitalizar a memória dos levantes, que reivindicavam Tupac Katari, líder indígena do século XVIII, nas comunidades.

Depois de deixar o THOA e abandonar, por um tempo, sua carreira como professora universitária, desenvolveu a sociologia das imagens como práxis descolonizadora (CUSICANQUI, 2015). Um dos objetivos dessa metodologia é romper com o oculocentrismo e com a fissão entre imaginação e localização, conforme falamos acima. Também existe a proposta de evidenciar que a produção de conhecimento passa por linguagens visuais e corporais, e não apenas pela linguagem grafocêntrica - pela escrita.

Um dos contextos de elaboração da sociologia das imagens é a crítica à cultura escrita e ao grafocentrismo dentro das universidades. Nessa perspectiva, a escrita, no contexto da colonização, existe para encobrir a realidade. Em contextos coloniais, o escrever é uma remissão ao poder - ao Imperador, ao império, ao Estado. Lendo isso, penso nos ritos acadêmicos de legitimação da palavra dentro da universidade e que estão, parece-me, associados à construção dos dois níveis de exclusivismo epistêmico: a ideia de que teoria é coisa de homens brancos do Norte e a percepção de que no Sul o conhecimento é a produção de homens e mulheres brancas - ou embranquecidas - que aplicam aqui teorias do Norte. Conectada a essa questão está a exclusão de quem não domina a gramática e a escrita. Cusicanqui (2015) conta que os estudantes, especialmente os de origem indígena, e que têm no espanhol - e português - a segunda língua, ainda são vítimas do que chamaria de uma terceira camada de exclusivismo. Para as universidades, o conhecimento deve estar escrito e grafado nas línguas ${ }^{41}$ do colonizador: inglês, francês, alemão, espanhol, português etc. A conexão entre colonização, universidade e conhecimento está , ainda, conectada ao fato de que as línguas indígenas, para a autora, sofreram uma destituição epistêmica. Poderíamos perguntar: Por que passamos anos trabalhando na categoria-metáfora logos e pouco fizemos com as categoriasmetáforas ameríndias (camponesas e amefricanas)?

\footnotetext{
${ }^{40}$ Para mais informações sobre o Taller ver: https://www.youtube.com/watch?v=P5iGTO0TjQM

41 Tenho em mente a razão calibanesca e o fato de que podemos usar a língua do opressor contra o opressor. Contudo, essa metáfora não pode conduzir à imobilidade. Podemos, ainda, escolher um cosmopolitismo linguístico que inclua línguas do Sul. Em situações de intenso colonialismo interno como em Bolívia e no Brasil, as línguas indígenas e o pretoguês podem ser forma potentes de r'existência
} 
O esforço de Cusicanqui em pensar com as línguas e episteme indígenas centra-se na categoria-metáfora Ch'ixi, que em aymara significa "algo es y no es a la vez [...] ch'ixi conjunga el mundo índio com su oposto, sin mesclarse” (Cusicanqui, 2010, p. 70). Sem virar o mestiço teleologicamente eurocentrado, homem e branco, o chi'ixi é aquele capaz de ser e habitar distintos mundos, o do colonizador e o dos colonizado, e produzir uma ruptura com a mistura teleológica eurocêntrica e racista, e que bloqueia a possibilidade de que saia detrás de nós, o índio e a índia (o amefricano e a amefricana, a camponesa e o camponês). Permite que caminhemos para frente, caminhando para trás, falando com os mortos. Segundo Cusicanqui (2018), as epistemes ameríndias fundam-se, também, em uma procura por dialogar com os mortos. Exemplifica isso com o culto dos mortos no México e nos Andes que, para ela, transcende uma dimensão religiosa e existe como procura por diálogo com o passado, um "pensar memorioso". O sentido desse diálogo é o futuro-passado: "Andar para frente é andar para o passado", como diz um aforisma aymara. Significa encontrar as forças do passado que têm futuro, não no sentido de encontrar um essencial pré-colonial, mas no sentido de desencobrir e dialogar com o pensamento produzido na r'existência ao colonialismo ${ }^{42}$.

Por fim, em uma entrevista no México, ela fala do Suma Quamaña, o Bem Viver Aymara $^{43}$. Como crítica da apropriação - e torção - por parte do Estado, diz que o que ela ouviu entre as comunidades aymaras foi "Viver bien". É, do ponto de vista epistêmico, andar como gente e falar como gente, o que implica escutar antes de falar, guardar o silêncio, colocar em prática o que é pronunciado e, acima de tudo, distribuir a palavra - deixar que todas e todos usem-na, pronunciem o mundo.

Além da distribuição da palavra e busca pelos mortos, a episteme indígena caracterizase por uma forma de lidar com a natureza, consumir os recursos naturais e saber fazer comunidade, mediada não pelo partido ou a organização, mas fazendo comunidade por autoconvocação.

Como intelectual que pisa o chão indígena (americano e camponês) das sociedades latino-americanas e amazônicas, Cusicanqui reivindica o "pensar memorioso". Trata-se do

\footnotetext{
${ }^{42}$ Aqui talvez eu esteja fazendo uma leitura de Cusicanqui a partir de uma fala de Gordon (2017). Ele afirma que os colonizados, por causa da colonização e violência, não interromperam o pensamento, mas o articularam à nova situação. Parece-me que essa é a mesma perspectiva de Cusicanqui e que ambos, por serem leitores de Fanon, remetem-se à crítica dele a certo perigo de essencializar as culturas dos povos colonizados.

${ }^{43}$ A ideia do Bem viver existe em Quéchua, no qual é grafado como Sumak Kawsay, em Aymara, Sumaq Quamaña e Guarani, Teko porã. Ver "Sumak Kawsa, Suma Qamaña, Teko Porã. O Bem-Viver." Disponível em http://www.ihuonline.unisinos.br/media/pdf/IHUOnlineEdicao340.pdf
} 
trabalhar as metáforas-palavras, os aforismas, das línguas e epistemes indígenas em oposição à episteme do norte-atlântico de formar, do descolonizar o presente pela memória do pensamento e da práxis descolonial, pois "no puede haber un discurso de la descolonização, uma teoría de la descolonización, sin práctica descolonizadora" (CUSICANQUI, 2010, p. 62).

\section{Desencobrir é práxis descolonizadora}

Como disse acima, o envolvimento com a episteme norte-atlântica alienou-me, durante muito tempo, das comunidades de vida, existência e r'existência dentro dais quais nascera. A escolarização, como norteamento, significou tampar meus olhos por dentro. Desde de 2015, dedico-me a desencobrir-me de dentro para fora e ao desencobrimento dos autores e autorias do Sul. Nas leituras que fiz, desde a antropologia cultural, das pós-coloniais à decolonialidade, Gordon, Fanon e Cusicanqui ajudaram a enfrentar os perigos de pensar a partir do Sul dentro das universidades, que se configuram, historicamente, como ilhas de Norte. O esforço a que me dedico é o de desnortear a universidade. Para isso, as instituições devem ser retaguarda das lutas descolonizadoras das comunidades de vida, existências e r'existência reais. De nada adianta ocupar as universidades com as autorias escritas e orais do Sul e transformá-las em uma nova ortodoxia.

Não quereremos novos senhores, não quero um novo senhor para o meu pensamento. Isso eu só sei explicar recorrendo a Gordon (2015). Ele diz que, durante muito tempo, insistiam em perguntar a qual filosofo europeu ele dedicar-se-ia. Como homem negro, segundo ele, por trás dessa pergunta estava o questionamento: “which philosopher will be my colonial master?”. "Colonial master" não funciona tão bem em português porque, como disse Grada Kilomba (2020), o Brasil é um experimento colonial exitoso, e está profundamente subjetivada em nós a cultura dos senhores coloniais, os do passado, os do presente e os do pensamento. Essa reflexão de Gordon (2015) reverberou muito porque, mesmo não sendo um homem negro, essa relação foi a que me mostrou dentro dos templos da episteme norte-atlântica, as universidades, em 20 anos dentro delas. Não há como pensar em um Senhor. Ao trabalhar para o pensamento desse senhor, aplicando-o à realidade, encobre-a e encobre-se como sujeito epistêmico.

Por isso, o esforço radical por deslocar as biogeografias da razão só pode conduzir-nos a assumirmo-nos como sujeitos epistêmicos, a aceitando-nos e aos outros sujeitos do Sul como sujeitos do pensamento e de sua história. Por isso, o pensamento do Sul sempre é um pensar memorioso. Penso com os pés neste chão, lembrando da violação pela qual todos os colonizados e escravizados passaram. Penso lembrando da luta radical destes contra os colonizadores, penso lembrando de Tereza de Benguela, Tupac Katari, Toussaint Louverture, Zumbi dos Palmares 
etc. Penso, como diria Cusicanqui, lembrando das "abuelas". Penso lembrando de C. L. R. James, Frantz Fanon, José Carlos Mariátegui, Mariguela, Osvaldão, Tuíre Kayapo. Penso, sobretudo, lembrando de Maria da Ilha, Dona Juscelina, Seu Cirilo, Dona Raimunda, Dona França, Dona Maria Mendes, Dona Aparecida etc. Penso, sobretudo, como as comunidades de vida, existência e r'existência do Sul, lembrando o futuro.

\section{Referências}

ALMEIDA, A. W. Os quilombolas e a base de lançamento de foguetes de Alcântara: laudo antropológico. Brasília: MMA, 2006.

APPIAH, K. A. Na casa de meu pai: a África na filosofia da cultura. São Paulo: Contraponto, 1992.

BHABHA, Homi K. O local da cultura. Belo Horizonte: Editora da UFMG, 2001.

CASTRO GOMES, S. La poscolonialidad explicado a los niños. Popayán: Editorial Universidad del Cauca, 2005.

CUSICANQUI, Silvia Rivera. Ch'ixinakax utxiwa: una reflexión sobre prácticas y discursos descolonizadores. Buenos Aires: Editorial Tinta Limón, 2010.

CUSICANQUI, Silvia Rivera. Sociologia das imagens. Miradas ch'ixi desde la historia andina. Buenos Aires: Editorial Tinta Limón, 2015.

CUSICANQUI, Silvia Rivera. Utopía ch 'ixi. Entrevista com Yael Weiss. 2018. Disponível em https://www.youtube.com/watch?v=pHJkCqe2gAk\&t=1605s.

DIRLIK, A. The Postcolonial Aura: Third World Criticism in the Age of Global Capitalism. Critical Inquiry. v. 20, n. 2, 1994,

DUSSEL, Enrique. Siete ensayos de filosofía de la liberación Hacia una fundamentación del giro decolonial. Madrid: Editorial Trotta, 2020.

ESCOBAR, Arturo. Sentir pensar con la tierra. Nuevas lecturas sobre desarrollo, território y diferencia. Medellín: UNAULA, 2014.

FANON, Frantz. Pele negras, máscaras brancas.Salvador: EdUFBA, 2008.

FANON, Frantz. Condenados da terra. Juiz de Fora: EdUFJF, 2005

FANON, Frantz. Alienação e liberdade. São Paulo: Ubu Editora, 2020.

FAUSTINO, Deivison Mendes. Frantz Fanon: um revolucionário, particularmente negro. 1. ed. São Paulo: Ciclo Contínuo Editorial, 2018.

FREIRE, Paulo. Pedagogia do oprimido. São Paulo: Paz e Terra, 2019. 
GEERTZ, ClifFord. O saber local: novos ensaios em antropologia interpretativa. Petrópolis: Vozes, 1997.

GEERTZ, Clifford. A interpretação das culturas. Rio de Janeiro: LTC, 1989.

GONZALEZ, Lélia. Primavera para as rosas negras. Diáspora Africanas: Editora Filhos da África, 2018.

GONZALEZ, Mario. O fortalecimento da comunidade: estratégias educativas, comunicativas e culturais. Pedagogias de[s]coloniais. Goiânia: EcoNuvem, 2020, pp. 128-141.

GORDON, Lewis. R. Decadência disciplinar e a de(s)colonização do conhecimento. Revista Epistemologia do Sul, Paraná, v. 1, n. 1, p. 110-126, 2017. Disponível em: < https://revistas.unila.edu.br/epistemologiasdosul/article/ view/784/653>. Acesso em: 28 jul. 2019.

GORDON, Lewis. R. Disciplining as a human science. Quaderna, Paris, n.3, 2015. Disponível em: <http://quaderna.org/?p=416>. Acesso em: 28 jul. 2019.

GORDON, Lewis. R. Shifting the geography of reason. 2019. Disponível em https://www.youtube.com/watch?v=ZGT5TTEwPGo.

GORDON, Lewis. R. Theory-critical, decolonial, Global, and Otherwise. 2019.Disponível em https://www.youtube.com/watch?v=NeZG5 5ckzU.

GORDON, Lewis. R. Decolonizing Knowledge - norms, methods and disciplinary decadence. 2015. Disponível em https://www.youtube.com/watch?v=-fsJnqdIFTE\&t=2485s.

GORDON, Lewis R. What Fanon Said. A philosophical introduction to his life and thought.

New York: Fordham University Press, 2015.

GORDON, Lewis. R. Decadencia disciplinaria. Quito: Abya-Ayala, 2013.

GORDON, Lewis R. Not always enslaved, yet not quite free: philosophical challenges from the underside of the new world. Philosophia, v. 36, n. 2, p. 151-66, 2008.

GORDON, Lewis R.; GORDON, Jane Anna. Not only the masters`s tools: African-American studies and theory and practice. Routledge, 2006.

HENRY, Paget. Caliban's Reason: introducing Afro-Caribbean Philosophy. New York, London: Routledge, 2000.

KILOMBA, Grada. O Brasil é uma história de sucesso colonial. 2020. Disponível em https://www.cnnbrasil.com.br/nacional/2020/06/06/o-brasil-e-uma-historia-de-sucessocolonial-lamenta-grada-kilomba.

MARX, Karl. "O processo de trabalho e o processo de valorização.” O capital. Vol. 01. São Paulo: Boitempo, 2017, p. 255-276. 
MIGNOLO, Walter. El pontencial epistemológico de la historia oral: algunas contribuciones de Silvia Rivera Cusicanqui. Estudios y otras prácticas intelectuales latinoamericanas en cultura y poder. Caracas: CLACSO, 2002. p. 1-16.

MIGNOLO, Walter. Histórias locais/desenhos globais. Colonialidade, saberes subalternos e pensamento liminar. Belo Horizonte: Editora da UFMG, 2003.

MOTOKI, C. As lutas camponesas e a utopia possível. Le monde diplomatique. 2020.

Disponível em https://diplomatique.org.br/as-lutas-camponesas-e-a-utopia-possivel/

MOUJAN, SILVA \& RAMOS (2020). Introdução. Pedagogias de[s]coloniais. Goiânia: EcoNuvem, 2020.

PORTELLI, Alessandro. História oral como arte da escuta. São Paulo: Letra e voz, 2016. PORTO-GONÇALVES, Carlos Walter; Leão, Pedro C. Da Rocha; LADEIRA, J. N.; CUIN, D. P.; SILVA, M N. Terra em Transe: geografia da expropriação e da r-existência no campo brasileiro 2018. In: Ruth Bautista Duran; Oscar Bazoberry Chali. (Org.). Acceso a la Tierra y Territorio en Sudamérica. La Paz: IPDRS-CIDES-UMSA, 2019, v. 1, p. 91-120. RAMOS, D. V.; MELO, M. A. Nação e narrativa em Pepetela. Locus (UFJF), v. 17, p. 174188, 2011. Disponível em https://periodicos.ufjf.br/index.php/locus/article/view/20333.

RAMOS, Dernival V. Encontros epistêmicos e a formação do pesquisador em História Oral. Revista História Oral. v. 22, n. 1, 2019. Diponível em http://revista.historiaoral.org.br/index.php?journal=rho\&page=article\&op=view\&path $\% 5 \mathrm{~B} \% 5$ $\mathrm{D}=871$

SANTOS, Boaventura de S. O fim do império cognitivo. Coimbra: Almedina, 2018.

SAID, Edward. Cultura e imperialismo. São Paulo: Companhia das Letras, 1995.

SMITH, Linda T. Descolonizando metodologias: pesquisa e povos indígenas. Curitiba: Editora da UFPR, 2018. 